\title{
Afectividad y creaciones estéticas: intervención social con jóvenes no cualificados
}

\author{
Affectivity and aesthetic creations: social intervention with unqualified \\ young adults
}

\author{
Chabier GIMENO MONTERDE \\ Universidad de Zaragoza, España \\ chabierg@unizar.es
}

Recibido: 30/05/2015

Revisado: 08/06/2015

Aceptado: 26/01/2016

Disponible on line: 01/07/2016

\section{Resumen}

Los jóvenes no cualificados, que participan en los dispositivos educativos de segunda oportunidad, recorren itinerarios de transición al mercado laboral cada vez más complejos. Por lo que conocer sus expectativas y su capacidad de agencia resulta ineludible para mejorar nuestro acompañamiento como profesionales de la intervención sociolaboral.

En este artículo exploramos la adaptación de esos jóvenes a una exigencia creciente de cualificación, que los está excluyendo laboralmente. Frente a este proceso, observamos que contraponen una resistencia basada en su capital simbólico, a través de la afectividad y la estética. Nuestro interés por estas respuestas nace de la desorientación percibida entre los profesionales de los programas educativos. Incapaces de comprender las trayectorias divergentes que estos jóvenes plantean, ante los itinerarios homogéneos que se les ofrecen para su inserción social.

Tras el análisis de las creaciones artísticas y estéticas de los adolescentes, intuimos que hay dos factores que activan su resistencia a las limitaciones de sus expectativas de éxito. Por un lado, una variable institucional, que apunta a una deficiente planificación de los itinerarios formativos, que los jóvenes perciben que les aboca a la infracualificación y a un mercado laboral precario e inestable. Y por otro lado, una resistencia a la exclusión, que se enraíza en un imaginario de éxito y de movilidad social propio de una juventud globalizada.

Palabras clave: desempleo, creatividad, fracaso escolar, acompañamiento, afectividad.

\begin{abstract}
Unqualified young adults who take part in second-chance education schemes face increasingly complex routes in entering the job market. As such, it is essential for professionals in socio-employment intervention to know these individuals' expectations and their capacity for agency, in order to improve support.

This article explores how these young adults adapt to a growing demand for qualifications that is excluding them from the working world. This exclusion, we conclude, is encouraging new forms of symbolic resistance, practised by young adults in social terms: the affective and the aesthetic. The author's interest in these responses arises out of the increasing disorientation among professionals involved in education programmes. These professionals are unable to understand the diverging paths preferred by these young adults to the homogeneous routes offered to them for purposes of social integration.

After analysing the adolescents' artistic and aesthetic creations, we conclude that two factors stimulate their resistance to the limitations placed on their prospects for success. First, there is an institutional variable that indicates a planning of training itineraries that these young adults perceive as leading them toward under-qualification and into a precarious and unstable job market. Second, there is a resistance to this exclusion, drawing upon an imagined construct of success and social mobility belonging to a globalized youth.
\end{abstract}

Keywords: unemployment, creativity, academic failure, accompaniment, emotions.

Referencia normalizada: Gimeno Monterde, C. (2016): «Afectividad y creaciones estéticas: intervención social con jovenes no cualificados». Cuadernos de Trabajo Social, 29(2): 263-274.

Sumario: Introducción. 1. Metodología. 2. Resultados de la investigación. 3. Conclusiones y propuestas. 4. Referencias bibliográficas. 


\section{Introducción}

Los trabajadores sociales, y otros profesionales que intervenimos en programas educativos y de inserción laboral con jóvenes no cualificados, llevamos tiempo desorientados como técnicos. Nuestra brújula gira sin indicarnos claramente hacia dónde van estos adolescentes que catalogamos como «en riesgo de exclusión», y diagnosticamos como difícilmente insertables laboralmente. Todos ellos son los protagonistas de nuestras intervenciones en los centros de segunda oportunidad académica y en otros dispositivos, surgidos en los años 1990, para incluirlos socialmente a través de la formación y el empleo como: aulas taller, programas de cualificación profesional inicial (PCPI), formación profesional básica, etc.

Esta investigación tiene por objetivo ayudarnos a reflexionar sobre el papel que juega la creatividad estética de estos jóvenes en nuestro acompañamiento como profesionales, como generadora de vínculos y refuerzo de su resiliencia. Tras el análisis de las estructuras simbólicas (Bergua, 2011, p. 151) que subyacen en las expresiones artísticas de estos jóvenes, hemos corroborado lo que expresa una corriente creciente de profesionales, en el sentido de que lo estético está profundamente ligado a lo afectivo; así como que nos permite introducir mejoras sustanciales en la creación de vínculos, como elemento clave de toda intervención sostenible $\mathrm{y}$ transformadora (Gimeno, 2014b).

\section{Metodología}

La investigación que hemos llevado a cabo tiene una finalidad aplicada, partiendo de fuentes de información vinculadas a la intervención socioeducativa. Los datos obtenidos provienen de nuestra práctica profesional en tres contextos formativos con varones: dos formales (programas de cualificación profesional inicial y aula taller) y uno no formal.

En primer lugar, durante los cursos de 2007 a 2012 realizamos dieciséis entrevistas semiestructuradas a alumnos y exalumnos de programas de cualificación profesional inicial, en varios centros ocupacionales de Zaragoza, con edades entre los 16 y los 21 años. Durante este periodo, también participamos con ellos en la creación de perfiles en las redes sociales virtuales (Facebook y Tuenti), base de una etnografía diacrónica en la que hemos trabajado con más de 1.500 fotografías y sus correspondientes etiquetas.

En segundo lugar, durante el curso 20132014, realizamos igualmente una etnografía y una observación, esta vez con veintisiete adolescentes (14-15 años) participantes en dos aulas taller, en Zaragoza. Junto a ellos también realizamos una batería de actividades artísticas, que concebimos como «relaciones improbables con la estética». En ambas fases de la investigación fuimos registrando en cuadernos de campo los resultados de la observación participante, incluyendo los discursos de otros profesionales implicados en la intervención.

$\mathrm{Y}$, en tercer lugar, para validar algunas de nuestras intuiciones sobre el imaginario globalizado de estos jóvenes, comparamos las creaciones observadas con las surgidas durante los talleres de expresión artística, realizados por la activista e investigadora Mara Gabrielli en Barcelona, entre 2011 y 2012. Los seis adolescentes participantes en esa experiencia, de origen migrante, acudían a actividades de socialización y educación no formal en SOS Racisme-Catalunya.

Todos los jóvenes acompañados han tenido trayectorias escolares divergentes de los itinerarios homogéneos que el Estado les ofrece para su inserción laboral. En el caso de los jóvenes observados en Zaragoza, los primeros lo fueron en un contexto formativo postobligatorio (programas de cualificación profesional inicial). Y la muestra elegida para las entrevistas no ha sido aleatoria, sino que se ha buscado que representara perfiles por zonas geográficas de origen (Magreb y África Subsahariana). En el caso de los adolescentes derivados al aula taller, fueron externalizados por varios Institutos de Educación Secundaria a un Centro sociolaboral municipal (gestionado por una ONG local), tras sus conflictos conductuales. A los centros como el observado, asisten una mayoría de varones (el 70 por ciento), que no han superado curricularmente el segundo curso de la Educación Secundaria Obligatoria; con una presencia del 25 por ciento de menores gitanos y el 30 por ciento de jóvenes de origen extranjero. Entre ellos, además, aumenta el número de menores provenientes de clases medias depauperadas por la actual crisis económica (Gracia, 2013).

En ambos casos ha sido clave la «observación flotante» (Pétonnet, 1982), estando siempre dispuestos a no fijar nuestra atención en per- 
sonas o acciones concretas, y dejando «flotar» nuestra mirada, para que las informaciones no fueran filtradas por nuestro perfil profesional.

Algo similar ha ocurrido con las etnografías en las redes sociales virtuales o netnografias (Kozinets, 2010). En ellas hemos deambulado por los espacios y escenarios virtuales por los que transitan los jóvenes (Delgado Ruiz, 2003, p. 22), tal y como sugería la dérive situacionista (Debord, 1958 , p. 20). De esta forma, compartiendo perfiles en estas redes, la netnografia nos ha permitido observar, por un lado, los vínculos emocionales entre los jóvenes, más allá de sus estados individuales. Con lo que hemos accedido a su afectividad: sus emociones, sentimientos y pasiones. Y, por otro lado, hemos observado tanto la estética juvenil accesible públicamente on line, como la accesible sólo a los etiquetados como pares virtuales. A través de esa ventana a las relaciones mediadas telemáticamente, tenemos también un acceso continuo a los jóvenes acompañados. Lo que finalmente nos ha exigido, para no generalizar creatividades individuales, triangular la observación con más de un grupo de referencia (Kozinets, 2002, p. 64), en este caso en otra ciudad.

\section{Resultados de la investigación}

\subsection{Jóvenes no cualificados e inserción socio- laboral}

La coordinadora se queja de los [alumnos de $\mathrm{PCPI}$ que no quieren estudiar, que no les interesan los cursos [de oficios de la construcción], ni trabajar de peones. Todos quieren ser futbolistas, cantantes, famosos (Cuaderno de campo, febrero de 2012).

Los dispositivos formativos y prelaborales que estudiamos surgieron en el periodo final de la inserción social a través del empleo, en el ocaso del siglo pasado. En una etapa histórica de Europa en la que la industria y otros sectores económicos todavía empleaban a jóvenes con cualificaciones de nivel académico bajo. Se trataba de actividades que ocupaban a un extenso volumen de trabajadores en cada unidad productiva. Pero ese ciclo parece estar agotado y, a decir de algunos análisis, la sociedad laboral se acerca a su fin, dejando espacio para nuevas socializaciones (Virno, 2003a, p. 64). La elevada tasa de paro juvenil parece que no puede seguir achacándose a las crisis cíclicas. Al contrario, sería una consecuencia exitosa de un capitalismo tecnológicamente avanzado, que precisa cada vez menos mano de obra (Beck, 2007, p. 11). Y, aun menos, mano de obra infracualificada.

Entonces ¿cuál es la nueva relación entre lo laboral y estos jóvenes en situación (o riesgo) de exclusión? ¿Cómo se adaptan a un mercado laboral con una exigencia creciente de cualificación? En nuestro análisis intuimos que su exclusión del mundo del empleo está anudada a nuevas formas de resistencia simbólica, ejercidas por los jóvenes a través de las socialidades: lo relacionado con lo estético y lo afectivo. A través de ellas mantienen un nuevo tipo de vínculo con sus iguales. Un «ser-con-los-otros» que pone el acento en la interacción y la reciprocidad constante (Maffesoli, 2000, p. 190), característica también de lo virtual, generando nuevas formas de solidaridad y generosidad (Gimeno, 2014a, p. 55).

La alegría e ilusión, percibidas como desinterés, reflejan una expansión de la dinámica existencial (Maffesoli, 2000, p. 163), que resulta a menudo aberrante $o$ insensata para quienes trabajamos encauzando las conductas hacia la sociedad del empleo. De ahí que, para algunos técnicos, los jóvenes no cualificados puedan ser tratados simplemente como residuos (Bauman, 2005, p. 24), como todo lo que tiene que ver con esa nueva subclase, «la parte de la clase trabajadora sin ambición ni aspiraciones» (Jones, 2013, p. 16).

Frente a esa racionalización perversa de nuestra desorientación profesional, en nuestras etnografías observamos una juventud que, ajena a estos juicios morales y debilitados sus vínculos con lo laboral, retoma su soberanía temporal. De hecho, Beck (2007, p. 22) nos recuerda que en las polis griegas los contrarios de lo laboral eran la libertad, la participación y otros privilegios. Por lo tanto, nuestra intervención social, deudora de la vieja moral fabril que desde la Ilustración ha identificado el trabajo con el orden y con la participación de la condición de ciudadanía, ¿no estará abocando a estos jóvenes no cualificados hacia lo que queda fuera de la democracia, asumiendo quizá un perfil securitario?

Hay que reciclar los materiales varias veces. No se trata de que aprendan. Estos chicos no van a trabajar nunca. Están aquí porque en la calle estarían peor (Director de centro, cuaderno de campo, diciembre de 2008).

$\mathrm{Si}$, por el contrario, y como nos invita a hacer Healy (2001, p. 52), contemplamos nuestra activi- 
dad como un Trabajo Social transformador, que facilita el desarrollo de capacidades y acciones de interés colectivo, como la creatividad estética (Delgado, 2000, p. 214), debemos estar atentos a esta nueva socialización post-empleo. La intervención clásica en los dispositivos sociolaborales, que algunos analistas anglosajones denominan «política del resentimiento», obliga a la persona vulnerable a permanecer al margen, sobre todo de las resistencias en las tensiones entre capital y trabajo, y a hablar desde su posición de víctima (Healy, 2001, p. 175). Por lo que la cotidianeidad, y las relaciones de poder que en ella se expresan, los técnicos no las piensan como espacios de transformación. Esta invisibilidad de la capacidad de agencia de los jóvenes convierte a menudo nuestra práctica profesional en paternalista y autoritaria a los ojos de los propios jóvenes (Dardier et al., 2013, p. 19), como pronto veremos.

Desaprovechamos así nuestro mayor potencial. Pues la relación de cercanía y espontaneidad que se establece diariamente entre profesionales y adolescentes, lo que comúnmente llamamos el vínculo educativo, es muy distinta a la de otros entornos de los Servicios Sociales, al participar en un marco-proyecto y una tarea comunes (Pérez Eransus, 2010, p. 104). Con ese magnetismo mutuo (Gimeno, 2014c, p. 61), el acompañarlos como sujetos creativos permite que, incluso, prácticas y discursos que se consideran desviados o marginales puedan convertirse en destrezas y en recursos para la resistencia y el cambio (Healy, 2001, p. 153). Lo que nos devuelve a un escenario que, como proyectos de inclusión social, habíamos abandonado: el de una intervención social que priorice la prevención y la promoción (Álamo, 2013, p. 59); no como una enumeración hueca, sino como una clave central del acompañamiento en grupo (Arija, 2004, p. 99). Como el árbol Ginkgo Biloba, que revivió al cabo de un año, tras la bomba lanzada en Hiroshima, el arte urbano, la música y otras expresiones individuales y comunitarias simbolizan la resiliencia frente a la exclusión académico-laboral, la disposición a resistir y mejorar sus propias vidas.

\subsection{Más allá de la cualificación para el em- pleo: estrategias juveniles de movilidad social simbólica}

¿Chicos de éxito? (...) Son los chicos que tienen un potencial de autonomía, de resiliencia, de fortaleza, de ganas de tirar hacia delante (...) Y no sólo el chico que cumple con todo lo que se le pide, el chico responsable (Educador entrevistado, Barcelona, 2012).

Entre los resultados de nuestro análisis planteamos dos factores clave, como movilizadores de las resistencias juveniles al poder hegemónico (aquel que limita las expectativas de éxito): su percepción de las políticas educativas de segunda oportunidad, dirigidas a reorientar su deserción de los itinerarios escolares estandarizados, y sus estrategias de movilidad social al margen de las estructuras simbólicas establecidas por el Estado para ellos.

La primera variable desencadenante de las resistencias nos remite a una percepción, expresada por los jóvenes entrevistados: que la planificación de estos itinerarios formativos los aboca explícitamente a la segregación social y a la infracualificación (Dipaola, 2010), vinculándolos a un mercado laboral secundario, precario e inestable (García Gracia, Casal Bataller, Merino Pareja y Sánchez Gelabert, 2013, p. 87).

Frente a estas limitaciones de lo instituido, los jóvenes no ejercen una oposición o una resistencia en clave de superación o modificación de aquéllas, siguiendo el patrón de la primera modernidad, sino que eluden dicho enfrentamiento, ejerciendo una deserción o éxodo biográfico (Virno, 2003a, p. 74). De forma que crece el número de exalumnos que retornan a la formación reglada como adultos no cualificados, al superar la mayoría de edad. Desarrollan itinerarios de formación más elásticos y con mayor amplitud temporal, en los que su capacidad de agencia aflora de nuevo, al superar las barreras burocráticas que suelen dificultar su retorno formativo, administrativamente no previsto (García Gracia, Casal Bataller, Merino Pareja y Sánchez Gelabert, 2013, p. 78).

La implicación de los diseños de las políticas educativas en su exclusión sociolaboral no les permite asociarse en los dispositivos a los escenarios de movilidad social ascendente. Más bien, los jóvenes no cualificados son encauzados por estas segundas oportunidades bajo una paradoja: que lo legislado como un ascensor social, deviene a menudo una puerta giratoria que alimenta nuevas formas de segregación social (Mucchie1li, 2012, p. 10). Ni en los momentos de aparente bonanza cíclica del capitalismo, estos jóvenes percibieron que los dispositivos de inserción les 
permitieran dejar atrás su estigma (Santelli, 2007, p. 276). Por lo que la aparente oportunidad colectiva que ofrece el Estado de bienestar en estos casos deviene un riesgo de exclusión individual (Beck, 2007, pp. 78 y 80).

El centro de nuestro análisis en este texto, con todo, está en la segunda de las resistencias observadas ante esa segregación: la movilidad social a través de la creatividad juvenil. Una dimensión emergente que se ha de incorporar en nuestros acompañamientos educativos. Esta resistencia simbólica sorprende a los profesionales implicados, pues se nutre de un imaginario de éxito basado en lo estético y lo afectivo. Estas socialidades coinciden con las presentes en Europa entre los categorizados como NEET o not in employment, education or training (Eurofound, 2012): los chavs $^{1}$, la racaille ${ }^{2}$, los canis y otros perfiles juveniles establecidos por lo instituido, en otro ejercicio de performatividad. Y, al mismo tiempo, denotan la importancia del autoconcepto, en una juventud global, reconocida y explotada comercialmente en cuanto icono de la libertad (Dell'Umbria, 2009, p. 41), y de la que también forman parte los no cualificados. En las aulas observadas, esto se confirma cuando, a final del curso, los jóvenes entrevistados tienen una visión más positiva de sí mismos, tras la incorporación de estos imaginarios en el proceso formativo. Lo que les hace sentirse más capaces y motivados para continuar formándose (Madroño, 2014).

Si acercarnos a estas estructuras simbólicas nos permite acompañar mejor a los jóvenes, es preciso conocerlas para evitar la actual colisión de expectativas entre profesionales y alumnado. En esa aproximación, nuestro análisis de las socialidades nos ha permitido establecer diversos aglomerados estéticos, determinar algunas resistencias afectivas y observar la transversalidad del consumo y la movilidad geográfica en la juventud globalizada.

Comenzando por la estética, hemos podido situar a los jóvenes acompañados en torno a los borrosos límites de varios nodos. Se trata de estéticas efímeras (Pérez, 2011), que se alejan de la estabilidad de los perfiles industriales de la ex- clusión, esperados por los profesionales: la austeridad y el ascetismo obrerista (Beck, 2007, p. 129), el civismo del asistencialismo welfarista, etc. La exuberancia de su estética, por el contrario, escandaliza a la ingeniería social y a sus técnicos (Jones, 2013, p. 17), por estar anudada a la celebridad, vía preferente para comunicarse en la sociedad del consumo (Dell'Umbria, 2009, p. 13). Y tampoco se encuadran estéticamente con uniformidad, por lo que a menudo se afirman como afines a dos o más estéticas, inmersos cómodamente en la borrosidad.

La recodificación de los discursos y las imágenes procedentes de las netnografias, analizadas durante estos años, nos permite señalar un sustrato común, con aglomerados que hemos centrado en el origen étnico y social de los jóvenes (Cuadro 1). Por un lado, los jóvenes gitanos, que se mantienen como un perfil estable en estos dispositivos desde los primeros años 1990, a pesar de la irrupción de los jóvenes migrantes en este siglo (Gracia, 2013). Lo que nos remite a una clara exclusión del sistema escolar, que los ha segregado a lo largo de varias leyes educativas (ERIO, 2013). En torno a ellos, agrupamos también a otras alteridades educativas, como los jóvenes mestizos (quinquis y mercheros), los $c a$ nis y otro lumpemproletariado postindustrial, que comparten con los jóvenes gitanos estética y afectividades.

Los otros dos aglomerados agrupan al alumnado de origen extranjero, sean ellos los migrantes o sus familias, y a los jóvenes autóctonos del estrato más depauperado. Estos tres perfiles comparten la infracualificación (exclusión académica) y la práctica del parkour económico (exclusión laboral). Lo que les sitúa fuera incluso del «precariado», espacio social del que proceden otros jóvenes más cualificados, con mayor capacidad de agencia en sus estrategias de movilidad social a través del empleo regulado.

Estas estéticas, a las que podrían sumarse otras, son fruto de una desbordante creatividad juvenil y apuntan un continuum en el que los híbridos entre los aglomerados étnico-sociales confluyen en la subcultura rap. Esta es la más global de las expresiones culturales juveniles,

1 Joven blanco, no cualificado, dependiente de la asistencia social, homófobo y racista, protagonista de un estereotipo británico contemporáneo sobre la clase obrera post-industrial (Jones, 2013).

2 Es el término francés para «chusma», y se utiliza para designar a los jóvenes de los barrios periféricos de viviendas sociales. 


\begin{tabular}{|c|c|c|}
\hline Aglomerado & Estética & \\
\hline \multirow[t]{4}{*}{ Gitano } & Metrosexualidad y ultraviolencia & \\
\hline & Evangelista/Gente de orden & \\
\hline & Maquinero/cani & Híbrido: gitano/depauperado \\
\hline & Quinqui rapero & Híbrido: gitano/depauperado \\
\hline \multirow[t]{2}{*}{ Depauperado } & Rapero & $\begin{array}{l}\text { HÍBRIDO CLAVE: } \\
\text { gitano/depauperado/migrante }\end{array}$ \\
\hline & Rasta/fumeta & Híbrido: depauperado/migrante \\
\hline \multirow[t]{2}{*}{ Migrante } & Banlieusard & \\
\hline & Magrebí gangsta & \\
\hline \multirow[t]{2}{*}{ Renuentes o outsiders } & Siniestro/tecno & \\
\hline & Geek & \\
\hline
\end{tabular}

Cuadro 1. Estéticas en los centros de segundas oportunidades (2007-2014).

que atraviesa las diferentes extracciones sociales y que actúa como clave de este arco de estéticas. El joven que utiliza el rap comulga así con otros muchos. Recordándonos que incluso los muchos necesitan ser uno, y que esta unidad se expresa mejor con el lenguaje, la facultad común (Virno, 2003b, p. 26). Esta cultura musical incluye en su abanico de estilos, el gangsta rap, como himno a la competencia individual despiadada (Dell'Umbria, 2009, p. 43). Y aún deja espacio, como sucede siempre que nos alejamos de lo estable o instituido, a resistencias de segundo nivel: las de los outsiders, los jóvenes que se quieren alejar de los aglomerados estéticos vinculados al destierro académico, y que se nutren, casi siempre, de estéticas con nodos en otras precariedades juveniles: aquellas con mayor acceso a la cualificación de primer nivel (góticos, tecno, etc.). Por lo que les permiten tener vidas mestizas, dentro y fuera de la exclusión educativa de estos dispositivos.

En segundo lugar, nuestro análisis de las sociabilidades presentes en los collages, blogs, micro-relatos y otras creaciones artísticas experimentadas, nos sitúa ante una compleja resistencia afectiva, que oscila entre el amor y la rabia, y que aquí aparece vinculada a la resiliencia grupal de las redes de iguales, cada vez más virtualizadas, y a la extensión consiguiente de las estrategias de buscavidas. Liquidadas las ante- riores seguridades welfaristas, la idea de que para cada consecuencia de la modernidad hay una solución racional es cada vez más cuestionada (Beck, 2007, p. 38). Y más aún cuando se hace necesario el concurso del Estado. Frente a la precedente superposición entre éste y la sociedad, los jóvenes no cualificados contemplan muchos más modos de acción, de trabajo y de vida económica, a menudo fuera del contenedor estatal (Mucchielli, 2012, p. 5): nuevas formas de buscarse la vida.

La masiva ausencia de empleo les afecta especialmente y desplaza también el sentido de otras claves sociales, como los conceptos de justicia-injusticia, la autodefinición a través de la especialidad laboral y la propia participación en la sociedad-democracia. Los jóvenes entrevistados reconocen que se les propone una vida en la que todo es posible y en la que nada ni nadie es ya previsible. Lejos de las casi olvidadas normas fordistas del pleno empleo, el siguiente paso es aceptar que lo ilegal-legal es también un constructo social, proveniente de un contexto industrial concreto, ajeno al actual (Beck, 2007, p. 94). Quizá por ello, frente a la camisa de fuerza farmacológica (Dell'Umbria, 2009, p. 15), entre las afectividades juveniles emergentes que hemos observado, surge homeopáticamente el vandalismo, como expresión de ira y de alegría, ambas ligadas: 
[Alumno de aula taller] cuelga en el blog de clase un video de Nyno, su rapero gitano favorito. Me cuenta que le gustaría ser como él, para que le respeten en su barriada. Ayer llegó con hematomas a clase. La letra dice: «La calle es solo la calle, hermano, no hay mayor escuela. Aquí el que juega con fuego, tú sabes primo, se quema. La voz que suena en la calle, te mato sin darte detalle (...). Camina pa la orilla, evita que nos encontremos $»^{3}$. Repite nervioso esta última frase (Cuaderno de campo, noviembre de 2013).

En el collage virtual que hacen para mi despedida, [Alumno A.] me dedica una foto con la frase que tanto le gusta de Nyno, porque dice que a mí no me ha asustado ni su música ni él. Me da un abrazo (Cuaderno de campo, marzo de 2014).

Estas afectividades tan anudadas, como el continuum ira-alegría, justo-injusto, verdadfraude, regular-irregular, tras el análisis simbólico de las netnografias nos ofrecen un mapa con varios centros de interés. Nodos que hemos clasificado en el siguiente Cuadro 2.

La movilidad social por medio de estructuras simbólicas, ajenas a las establecidas por lo instituido para los adolescentes no cualificados, arranca desde un primer nodo, quizá el principal, formado por imágenes y textos sobre el consumismo adolescente, propio del capitalismo contemporáneo. Consumo de bienes y adscripción a iconos deportivos globales forman parte de un imaginario del éxito ante el que es preciso marcarse (Ibáñez, 1989, p. 178), para lanzar multidireccionalmente en las redes virtuales un mensaje implícito de que están en la ola, como el resto de los surfistas (Bauman, 2002, p. 189). Surfear rápido, no bucear en lo profundo: De eso se trata la vida, como se ve en la tele (Alumno de PCPI, Cuaderno de campo, febrero de 2011).

El éxito de un surfista, como el de estos adolescentes, depende de su habilidad para mantenerse sobre la superficie... del consumo universal. Consumir, como después veremos también, es la vía para la integración en la estructura simbólica globalizada que se ha instituido para los jóvenes cualificados. Al contrario que en la estructura simbólica de victimización y exclusión, que ciertos técnicos educativos pueden haber conformado implícitamente para los jóvenes no cualificados.

Eso no saldrá bien. Trabajamos con lo peor. ¡Son unos delincuentes!» (Educador. Cuaderno de campo, noviembre de 2013).

¿Informática? Lo van a destrozar todo. Estos chicos no son normales. No pueden aprender como nuestros hijos (Educador. Cuaderno de campo, octubre de 2013).

La potencia simbólica y discursiva del consumismo se refleja en casi toda la muestra de perfiles virtuales elegidos. Por ejemplo, en los textos y las imágenes que exhiben coches (y motos) de alta gama, a modo de exvotos paganos. Además de las fotografías que muestran a los jóvenes vestidos según los patrones de estética y elegancia casual, propios de los estándares económicos emulados. Aunque el recurso a la visualización del dinero es, sin duda, el clímax de esta rama del imaginario on line.

El segundo nodo, lo deportivo, es también el nexo con la otra rama del imaginario: el cuerpo. Las referencias al deporte reflejado en los murales, la cerámica u otras creaciones artísticas

\begin{tabular}{|c|c|c|}
\hline Nodos & Contenidos & \\
\hline Consumo & Motos, coches, ropa, deportivas, billetes & \\
\hline Deporte & Iconos del fútbol, deporte practicado & EI \\
\hline Cuerpo & Vigor social, mercado sexual & 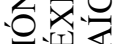 \\
\hline Ocio & Ocio diurno, ocio nocturno & 更坐 \\
\hline Música & Comercial, rap, étnica & ¿ొڤ \\
\hline Empleo & Formación profesional, puestos de trabajo o prácticas & 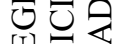 \\
\hline Raíces & Música étnica, indumentaria, gastronomía & 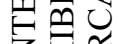 \\
\hline Familia & Nuclear y extensa & Z西要 \\
\hline Vida comunitaria & Social, religiosa, familiar & $\sum$ \\
\hline
\end{tabular}

Cuadro 2. Redes sociales y resistencias afectivas.

\footnotetext{
${ }^{3}$ Véase en https://www.youtube.com/watch?v=p9MDi6gHp54
} 




Imagen 1. Collage con exhibición de billetes.

marcan al joven sano y con éxito, según las prácticas de socialización hegemónicas; pero también dan el salto hacia el cuerpo exhibido como indicador del vigor social. Un vigor físico que actúa como indicador de bienestar económico. Más allá de lo que la musculación, la belleza o la proporción muestran en el plano meramente deportivo o instituido, la exhibición corporal constituye un significante que remite a significados muy diversos en lo instituyente. Los discursos off line de los jóvenes observados y los textos on line de otros y otras jóvenes con los que comparten los perfiles, remiten sin duda a un significado de posición en el mercado sexual y a la posibilidad de asociar movilidad estético-afectiva y movilidad económica.

El resto de los nodos, como el del ocio o el de la música, confluyen en la música étnica, quizá la bisagra entre dos aglomerados de afectividades. Si el primero, recién descrito, nos remite al hedonismo globalizado, el segundo está conformado por todo lo referente a la seguridad que comporta lo local, al cariño y al amor que se dan en la familia y la comunidad. A los jóvenes alóctonos la música étnica les remite a su origen, donde tienen sus raíces culturales y comunitarias. Y a ellos, y a los autóctonos, las referencias al empleo o a las prácticas en empresas, como hito en su integración social, les sirven para exhibir ante sus iguales o ante sus vecinos y familiares su itinerario formativo hacia el éxito hegemónico: el acceso al mundo laboral.
Y aun así, aun presentándonos y acompañando esta parte de sus afectividades on line como profesionales de lo social (Del Fresno, 2013), somos conscientes de que sólo podemos intuir una parte de lo que permanece en sombras para la intervención social off line. Los perfiles de las redes dejan fuera mucho socius, que acaso con las netnografias y con las intervenciones artísticas en las aulas sólo podemos entrever como destellos fugaces. Admitiendo esto, asumimos también que las imágenes sociales que los jóvenes tienen en torno a su propia inserción sociolaboral no pueden ser disciplinadas por cierto Trabajo Social ni por sus herramientas (los dispositivos educativos de segunda oportunidad). Al contrario, el imaginario social de los jóvenes no cualificados se insinúa casi siempre en los silencios, la burla o la astucia con la que se resisten a las políticas categorizadas como sociales, que han impuesto en torno a ellos unas representaciones instituidas de victimización. Al margen de ellas, encontramos las fotos de adolescentes consumiendo alcohol y hachís en muchos perfiles virtuales. $\mathrm{O}$ al joven hiperadaptado a los dispositivos educativos, el «chico con éxito», que se muestra on line como un playboy de la noche:

El mundo es más Grande que un barrio (Alumno de PCPI, en Tuenti, septiembre de 2011).

Son imágenes y textos difíciles de encajar en nuestras prácticas profesionales, pero que forman parte del saber común compartido entre los jóvenes en las redes virtuales. Por lo tanto, nuestra posición, como externos, condiciona - como hemos aceptado para esta investigación - el acceso al imaginario de los jóvenes: situándonos en la puerta de entrada del mismo, esto es, en un punto ciego. De manera que, al actuar el Trabajo Social como filtro, apenas se percibe nada. Es un no-lugar desde el que el imaginario afectivo juvenil no es visible (Gimeno, 2015, p. 557), al permanecer oculto por la imagen instituida, la imagen de la víctima: «el chico sin éxito».

Nuestra capacidad para traspasar ese límite, reforzado por algunos protocolos profesionales y por los propios jóvenes, puede ser clave para establecer vínculos en los acompañamientos:

Viendo fotos de su familia en Tuenti, hablamos con [alumno] sobre los malos tratos que sufría por su padre. No menciona los abusos. Me dice que a veces va a verlo a [ciudad]. Su madre no 
se lo impide. (...) Habla con toda normalidad de cómo vive del menudeo y de las ayudas sociales. Pasa muchas tardes colocado con sus amigos. Al ver que no me asusta, se siente más relajado. Comienza a hablarme de sus consumos [de tóxicos] (Cuaderno de campo, febrero de 2014).

A menudo, provenientes de entornos familiares desahuciados económicamente, o de barrios donde la desaparecida solidaridad obrera ha sido sustituida por la asistencia social (Dell'Umbria, 2009 , p. 17), las netnografias nos muestran que la auto-victimización, la astucia o el fraude al propio sistema asistencial devienen una fuente de estabilidad (Beck, 2007, p. 143); especialmente para aquellos que no tendrían otra fuente consistente de ingresos. Estas estrategias les permiten, paradójicamente, atender otras actividades, entre ellas unos itinerarios formativos que se prolongan cada vez más, más allá de la mayoría de edad. Velan así por sus propios intereses, lo que nos remite de nuevo a su capacidad de agencia y a una esperanzadora resiliencia. En suma, vemos estas estrategias de buscavidas, como las analizaría Castoriadis (1990, p. 92), para quien, en nuestras sociedades, las únicas vías de reparación aceptables para la psique son la transgresión... o bien la patología.

\subsection{Consumo y movilidad geográfica: nodos transversales}

Las sociabilidades observadas, tanto estéticas como afectivas, reflejan por lo tanto el retroceso del trabajo remunerado, la individualización, la globalización, la revolución sexual contemporáneas, etc. Lo que nos permite orientar nuestra mirada, para concluir el análisis de estos imaginarios, hacia la transversalidad del consumismo y de la movilidad geográfica.

A lo largo de estos años, nuestra deriva por las biografías de muchos de estos jóvenes coincide en señalar que su transición a la edad adulta está cambiando, cada vez más, en cuanto a las pautas de consumo. Minimizar los gastos de reproducción y maximizar los gastos en estética, ocio, etc.; así como asumir la alternancia entre el trabajo regularizado y el irregular (para renovar permisos de residencia, por ejemplo), constituyen ya conductas normalizadas. Al contrario de lo que hacen algunos de sus iguales, vinculados familiarmente a la cultura del self made man, al esfuerzo aun dentro de la exclusión (Santelli, 2007, p. 277). Muchos otros jóvenes no cualifi- cados, en lugar de adoptar irreflexivamente un estilo de vida por tradición o por hábito familiar, hacen de ese estilo un proyecto personal, como la mayoría de la juventud global. Exhibiendo su individualidad, expresan su inserción en una multitud conformada por singularidades (Virno, 2003b, p. 76). A la que muestran su sentido de la estética, con la especificidad de su montaje de bienes, ropas, prácticas, experiencias, apariencia e inclinaciones corporales (Featherstone, 2000, p. 147). Esta ética o lógica del instante (Maffesolli, 2000, p. 73) nos permite afirmar que el consumo no es ese modo pasivo de absorción y de apropiación que oponemos al modo activo de producción. Detonante de conductas dentro y al margen de la ley (Mucchielli, 2013), el consumo es un modo activo de relación, no sólo con los objetos, sino con la colectividad y el mundo (Baudrillard, 2007, p. 223). Es un modo de actividad sistemática y de respuesta global en el cual se funda todo el sistema cultural de estos jóvenes, en tanto que sujetos globales. Nada más alejado del binomio victimización-criminalización desde el que intervenimos sobre ellos a menudo. El consumismo inmediatista permite a los jóvenes no cualificados, como al resto de sus iguales etarios, participar de una revuelta agonista: en la que se emulan a través de las redes sociales, sumergidos en la competitividad estética, la única en la que pueden universalizarse de forma inclusiva. No hay aquí antagonismos, sino desafíos que nos remiten al intercambio recíproco y premoderno (Dell'Umbria, 2009, p. 12). Ni tampoco un pensamiento utilitarista, sino una confianza en los lugares comunes (Virno, 2003b, p. 38), como lo es la estética juvenil global.

El otro elemento transversal que hemos observado a través de las actividades creativas es la movilidad geográfica. Lo móvil es clave en el imaginario juvenil global, pues, por su propia esencia se aleja de la vigilancia del panóptico local, concebido como inmovilidad absoluta. Aunque, como ocurre con otras sociabilidades, esta circulación huidiza a los poderes hegemónicos carezca de conciencia de sí, y no tenga reparos en aceptar el lugar de destino tal y como es, al mismo tiempo que puede rechazar los valores establecidos, sin sentir contradicción alguna (Maffesoli, 2004, p. 24).

Esta movilidad se plasma, en sociedades cada vez más diversas, en la presencia de jóvenes migrantes o descendientes de migrantes. Como 
un síntoma más de la ausencia de superposición entre sociedad y Estado, estos jóvenes y sus familias pueden concurrir en muchos servicios, entre otros los educativos, independientemente del lugar donde pagan los impuestos. En una Europa donde no pocas grandes fortunas recurren a pagar impuestos en paraísos fiscales, las familias transnacionales hace años que han internacionalizado el Estado de bienestar (Gimeno, 2014a, p. $65)$. Pues la proximidad social de las redes familiares no implica proximidad geográfica (Beck, 2007 , p. 45). Algo que son renuentes a aceptar los dispositivos locales de educación y de apoyo al empleo. Pues, al mismo tiempo que hacen públicos sus valores universales, son refractarios a estos espacios sociales transnacionales (Santelli, 2001, p. 189). Contribuyendo simbólicamente al global apartheid, en el que millones de trabajadores han sido declarados innecesarios o irrelevantes (Sassen, 2012, p. 145), e ignorando la tendencia a la super-diversidad de las sociedades postindustriales (Crul, Schneider y Lelie, 2013): en Aragón, el 19,02 por ciento de los jóvenes menores de 29 años son de origen extranjero.

\section{Conclusiones y propuestas}

El acompañamiento a los jóvenes participantes en los dispositivos educativos de segunda oportunidad, junto con las actividades artísticas, las entrevistas y las netnografias nos permiten formular algunas conclusiones, además de lanzar propuestas para incluir la creatividad estética en nuestra intervención.

En primer lugar, nuestra posición profesional, como externos a las sociabilidades juveniles, puede superarse mediante la virtualización de una parte de nuestra intervención (Del Fresno, 2013, p. 149). Una vez que participamos de esa dimensión de lo social, tanto el intercambio de saberes, superando la unidireccionalidad de la relación, como la inclusión de lo estético en el proceso educativo nos permiten crear o reforzar los vínculos, claves en estos grupos de edad.

En segundo lugar, dado que los itinerarios formativos son percibidos por los propios jóvenes como diseñados con carácter segregador, tanto académico como social, es preciso activar un Trabajo Social basado en la promoción. Superando así el asistencialismo al que se vinculan los jóvenes desempleados (Levené, 2011, p. 56), pero también los «no parados», aquellos que han renunciado ya a trabajar, y que concurren en los dispositivos, generando lo que Ulrich Beck (2007, p. 90) denominó «gueto de pobres». Para ello, la mejora de las expectativas de futuro de los jóvenes pasa por la inclusión de su capacidad de agencia en los planes de trabajo acordados. Los jóvenes deben partir de lo existente, asumiendo que se han descolgado de un itinerario homogéneo hacia un mercado laboral cada vez más exigente académicamente. Pero los profesionales también debemos concebir los itinerarios deseados por los jóvenes, vinculados a un éxito común a la juventud globalizada, como herramientas educativas imprescindibles hoy en día. Por lo que urge adaptar la oferta educativa, todavía industrial, a nuevos perfiles laborales viables, como la informática, la música, el deporte, etc. Así como apostar por actuaciones educativas de éxito, como las basadas en las comunidades de aprendizaje y desarrolladas, entre otros, por el Centro de Formación Profesional Básica de la Fundación ADSIS, en Vitoria-Gasteiz, referentes en buenas prácticas. Conocidas estas alternativas en marcha, obviarlas sólo limita las oportunidades y cercena la dignidad (Santelli, 2007, p. 281).

En tercer lugar, entendemos que, a través de las socialidades juveniles, podemos aspirar a acompañar, reforzando el trabajo con grupos y comunidades (Delgado, 2000, p. 34), y no a encauzar, con un trabajo exclusivamente individual. Quizá esa sea la única vía para erosionar unas resistencias afectivas que nuestra posición como agentes externos hace inevitables. Tal y como concluye García (2014, p. 22), es preciso un trabajo en red, de corresponsabilidad con los jóvenes, en el que sea clave la existencia de referentes adultos positivos para ellos (educadores, familiares, jóvenes egresados exitosamente, etc.). El retorno al entorno escolar, casi siempre como nuevos adultos, nos demuestra que, aun con itinerarios más largos y complejos, los jóvenes continúan identificando su cualificación con la autonomía. Acompañémosles en el desarrollo de sus expectativas creativas, tal y como lo hacen con las creaciones estéticas que muchos profesionales estimulamos. En palabras de Richard Sennet (2003), en esa autonomía creativa está la clave de la dignidad. 


\section{Referencias bibliográficas}

Álamo, J. et al. (2013). Metodología de la intervención comunitaria. Los procesos comunitarios. En J. Buades y C. Giménez (coords.), Hagamos de nuestro barrio un lugar habitable. Manual de intervención comunitaria en barrios (pp. 58-73). Valencia: Tirant lo Blanch.

Arija, B. (2004). Trabajo social con grupos. Un proceso de vinculación a través del arte. Trabajo social hoy, Extra 2, 91-114.

Baudrillard, J. (2007). El sistema de los objetos. México: Siglo XXI.

Bauman, Z. (2002). La sociedad sitiada. México: Fondo de Cultura Económica.

Bauman, Z. (2005). Vidas desperdiciadas. Barcelona: Paidós.

Beck, U. (2007). Un nuevo Mundo Feliz. Barcelona: Paidós. Edición original de 1999.

Bergua, J.A. (2011). Estilos de investigación social. Zaragoza: Prensas Universitarias de Zaragoza.

Castoriadis, C. (1990). Poder, política, autonomía. Archipiélago, 4, 91-109.

Crul, M., Schneider J. y Lelie, F. (2013). Superdiversity. A new perspective on integration. Amsterdam: VU University Press. Maurice Crul.

Dardier, A. et al. (2013). Les décrocheurs du système éducatif: de qui parle-t-on? En M. Beffy y H. Guedj, France portrait social (pp. 11-22). París: INSEE.

Debord, G. (1958). Théorie de la dérive. Internationale Situationniste, 2, 19-23.

Del Fresno, M. (2013). Un nuevo ámbito: trabajo social comunitario, internet, redes sociales y capital social online. En M. del Fresno et al. (coord.), Trabajo social con comunidades en el siglo XXI (pp. 149-200). Madrid: UNED.

Delgado, M. (2000). Community social work practice in an urban context: the potential of a capacity-enhancement perspective. New York: Oxford University Press.

Delgado Ruiz, M. (2003). Naturalismo y realismo en etnografía urbana. Cuestiones metodológicas para una antropología de las calles. Revista Colombiana de Antropología, 39(2), 7-39.

Dell’Umbria, A. (2009). ¿Chusma? Logroño: Pepitas de Calabaza.

Dipaola, E.M. (2010). Socialidades contemporáneas: dinámica y flexibilidad en relaciones comunitarias e identitarias. Nómadas, [On Line] 26(2).

ERIO. (2013). La inclusión del pueblo gitano a través de las experiencias educativas de éxito. Bruselas: ERIO-European Roma Information Office.

Eurofound. (2012). NEETs. Young people not in employment, education or training: Characteristics, costs and policy responses in Europe. Luxembourg: Publications Office of the European Union.

Featherstone, M. (2000). Cultura de consumo y posmodernismo. Buenos Aires: Amorrortu.

García, M. (2014). Itineraris d'abandonament escolar prematur i acompanyament a les transicions després de l'escola obligatòria. Fòrum: revista d'organització i gestió educativa, 35, 17-22.

García Gracia, M., Casal Bataller, J., Merino Pareja, R. y Sánchez Gelabert, A. (mayo-agosto, 2013). Itinerarios de abandono escolar y transiciones tras la Educación Secundaria Obligatoria. Revista de educación, 361, 65-94. doi: 10.4438/1988-592X-RE-2011-361-135

Gimeno, Ch. (2014a). Buscavidas. La globalización de las migraciones juveniles. Zaragoza: Prensas Universitarias de Zaragoza.

Gimeno, Ch. (2014b). Alternativas de escolarización externa: una revisión. En Congreso Internacional Infancia en Contextos de Riesgo, Universidad de Huelva.

Gimeno, Ch. (2014c). Recherche sur les migrations clandestines des jeunes et éthique du travailleur social-chercheur. Sociographe, 7, 51-70.

Gimeno, Ch. (2015). Cultural bricolage on minors who migrate on their own. En F. Sabaté (ed.), Perverse identities. Identities in conflict (pp. 527-560). Berna: Peter Lang.

Gracia, J.M. (2013). Experiencia de la escolarización externa en los Centros Sociolaborales: evolución del alumnado, resultados y trayectorias. En Jornadas de Intervención para la Prevención y Reducción del Abandono Escolar. Zaragoza: Instituto Municipal de Empleo y Fomento Empresarial.

Healy, K. (2001). Trabajo social: perspectivas contemporáneas. Madrid: Ediciones Morata.

Ibáñez, J. (1989). Publicidad: La tercera palabra de Dios. Revista de Occidente, 92, 72-96.

Jones, O. (2013). Chav's. La demonización de la clase obrera. Madrid: Capitan Swing.

Kozinets, R. (2010). Netnography. Doing Ethnographic Research Online. York: SAGE. 
Kozinets, R. (2002). The field behind the screen: using netnography for marketing research in online communities. Journal of Marketing Research, 39, 61-72. doi: http//dx.doi.org/10.1509/jmkr.39.1. 61.18935

Levené, T. (2011). Les politiques d'insertion: quelle pertinence pour les inemployables? Formation emploi, [On Line] 116.

Madroño, B. (2014). Cambio motivacional de los jóvenes en centros sociolaborales de Zaragoza. En XVII Conferencia de Sociología de la Educación, Bilbao.

Maffesoli, M. (2000). L'instant éternel. Le retour du tragique dans les sociétés postmodèrnes. París: Denoël.

Maffesoli, M. (2002). La part du Diable. Précis de subversión postmoderne. París: Flammarion.

Mucchielli, L. (2012). Une activité délinquante à défaut d'emploi? Chroniques du Travail, [On Line] 2.

Mucchielli, L. (2013). Violence: de quoi parle-t-on? Sciences Humaines, [On Line] 247.

Pérez, E. (2011). De lo efímero que deja huella. Imagonautas, 1, 27-51.

Pérez Eransus, B. (2010). Activación de las personas con especiales dificultades de acceso al empleo. Cuadernos Europeos, 8, 99-116.

Pétonnet, C. (1982). L'observation flottante. L'exemple d'un cimetière parisien. L'Homme, 22(4), 37-47.

Santelli, E. (2001). La mobilité social dans l'immigration. Toulouse: Presses Universitaires du Mirail.

Santelli, E. (2007). Grandir en banlieue. París: Éditions CIEMI.

Sassen, S. (2012). Una sociología de la globalización. Madrid: Katz.

Sennet, R. (2003). El respeto. Barcelona: Anagrama.

Virno, P. (2003a). Virtuosismo y revolución. Madrid: Traficantes de Sueños.

Virno, P. (2003b). Gramática de la multitud. Madrid: Traficantes de Sueños. 